\title{
Intenção Empreendedora e Motivação para Aprender de Estudantes do Curso de Ciências Contábeis
}

\author{
Cristiane Krüger \\ https://orcid.org/0000-0003-2271-6432
}

Graziele Medianeira Cavalheiro https://orcid.org/0000-0002-0496-4574

Vinícius Costa da Silva Zonatto https://orcid.org/ 0000-0003-0823-6774

Fabíola Kaczam

https://orcid.org/ 0000-0002-0460-9927

\section{Resumo}

Objetivo: Analisar a relação entre intenção empreendedora e motivação para aprender dos estudantes de Ciências Contábeis da Universidade Federal de Santa Maria.

Método: Ancorada na Teoria do Comportamento Planejado, tem-se como base teórica a intenção empreendedora de Liñán e Chen (2009) e a motivação para aprender de Tho (2017). Deste modo, a pesquisa é quantitativa, descritiva, tipo survey. Os dados foram obtidos por meio da aplicação do Questionário de Intenção Empreendedora (Liñán \& Chen, 2009) e do Questionário de Motivação para Aprender (Tho, 2017). Participaram da pesquisa 219 alunos do curso pesquisado. Os dados foram tabulados e analisados estatisticamente.

Resultados: Os resultados revelaram que a motivação para aprender, percepção comportamental e intenção empreendedora dos acadêmicos são moderadas, enquanto que atitude pessoal e normas subjetivas apresentam-se em razão alta. Além disso, não houve correlação significativa entre os constructos de motivação para aprender e intenção empreendedora. Ao aprofundar as análises, por meio de regressão, evidenciou-se que a intenção empreendedora influencia a motivação para aprender.

Contribuições: O presente estudo contribui para a compreensão de aspectos comportamentais dos alunos de Ciências Contábeis, oportunizando e incentivando o desenvolvimento de um comportamento mais motivado a apreender e empreender.

Palavras-chave: Comportamento empreendedor; ensino-aprendizagem em Ciências Contábeis; Contabilidade comportamental. 


\section{Introdução}

O empreendedorismo é um mecanismo que estimula a inovação, o desenvolvimento comportamental e, consequentemente, o desenvolvimento econômico (Liñán, Rodríguez-Cohard \& Rueda-Cantuche, 2011; Minello, Bürger \& Krüger, 2017). Nesse aspecto, Omri (2020) aponta algumas contribuições da iniciativa empreendedora como o crescimento do PIB, maior taxa de emprego e renda, e melhoria geral da qualidade de vida da sociedade.

Liñán e Fernandes-Serrano (2014) referem-se aos empreendedores como possuidores de uma perspectiva inovadora, atribuindo-lhes o experimento de novas técnicas, a introdução de novos produtos e a criação de novos mercados. Esses indivíduos se diferenciam dos demais pelo seu comportamento empreendedor. Para Schaefer (2018), este comportamento pode ser descrito por características particulares que alguns indivíduos apresentam frente às oportunidades, as quais são evidenciadas no modo de perceber, pensar e agir de forma empreendedora. Para Ajzen (1991) esse comportamento é mais bem previsto pela intenção.

Nesse sentido, a intenção empreendedora indica o esforço que a pessoa fará para realizar o comportamento empreendedor, ou seja, quanto maior a intenção de um indivíduo em realizar determinado comportamento, maior a probabilidade de que este comportamento se efetive (Liñán \& Chen, 2009). Ainda segundo esses autores, a intenção de realizar um comportamento empreendedor pode ser afetada por vários fatores, como necessidades, valores, desejos e crenças.

No contexto educacional, o ensino do empreendedorismo tem sido considerado um dos principais instrumentos para aumentar as intenções empreendedoras de empreendedores potenciais e nascentes (Liñán, Rodríguez-Cohard \& Rueda-Cantuche, 2011; Krüger, Bürger \& Minello, 2019). Estudantes expostos à educação empreendedora desenvolvem uma intencionalidade mais forte para o empreendedorismo $\mathrm{e}$ relatam atitudes mais positivas do que os estudantes que não receberam essa educação (Gieure, BenavidesEspinosa \& Roig-Dobón, 2020).

No entanto, o estudo de Silva, Krüger, Minello e Ghilardi (2019), revela que os alunos de Ciências Contábeis quando ingressam no curso apresentam alta intenção empreendedora, mas, ao final da graduação essa intenção reduz significantemente. Diante dessa lacuna insere-se o constructo de motivação para aprender que pode ter relação com essa redução. A motivação pode ser tida como crucial para se ter sucesso no processo de ensino-aprendizagem (Gopalan, Bakar, Zulkifli, Alwi, \& Mat, 2017).

Os alunos com níveis mais altos de motivação para aprender tendem a ser mais eficazes na aquisição de conhecimento (Tho, 2017). Além disso, a motivação para aprender influencia os processos de tomada de decisão em relação à direção e ao foco (Cole, Harris \& Feild, 2004), podendo ser necessária aos aspectos comportamentais. Diante disso, questiona-se: qual a relação entre intenção empreendedora e motivação para aprender dos alunos de graduação de um curso de Ciências Contábeis?

Em resposta a esse questionamento, tem-se como objetivo principal a análise da relação entre intenção empreendedora e motivação para aprender dos estudantes de Ciências Contábeis da Universidade Federal de Santa Maria (UFSM). De modo complementar, busca-se: identificar o perfil dos alunos de Ciências Contábeis da UFSM; mensurar a motivação para aprender dos alunos de Ciências Contábeis pesquisados, de acordo com o instrumento proposto por Tho (2017); medir a intenção empreendedora dos alunos pesquisados, de acordo com o instrumento proposto por Liñán e Chen (2009); associar os constructos e as variáveis de motivação para aprender e intenção empreendedora dos alunos de Ciências Contábeis; e determinar a influência da intenção empreendedora na motivação para aprender. 
Esta pesquisa justifica-se pela necessidade de compreensão da motivação para aprender dos acadêmicos de Ciências Contábeis e sua relação com a intenção empreendedora, tendo em vista que, segundo Malacarne, Brustein e Brito (2019), o sistema educacional em vez de estimular o comportamento empreendedor dos alunos ainda prioriza a formação de profissionais para serem empregados. Para esses autores, é desafiador estimular o empreendedorismo nas instituições de ensino superior.

Considerando que a educação para o empreendedorismo influencia a intenção empreendedora de maneira positiva, este estudo é motivado pela necessidade de esclarecer quais elementos desempenham o papel mais influente na definição da decisão pessoal de iniciar um empreendimento, isso permitiria o desenho de iniciativas educacionais mais eficazes (Liñán, Rodríguez-Cohard \& Rueda-Cantuche, 2011). Ele foca em estudantes de Ciências Contábeis, tendo em vista a necessidade de acompanhar o desenvolvimento dos empreendimentos contábeis, no que diz respeito à capacitação desses profissionais para que identifiquem oportunidades e inovem o mercado (Silva et al., 2019).

As contribuições desta pesquisa podem refletir em alunos, professores e na sociedade. A partir das evidências encontradas, os alunos podem conceber e desenvolver um comportamento em prol do empreendedorismo, bem como podem clarear as perspectivas em relação ao mercado de trabalho. Por sua vez, os professores podem compreender a motivação para aprender, fator que afeta a aquisição de conhecimentos pelos alunos, de maneira a contribuir na elaboração de metodologias de ensino com foco no desenvolvimento do comportamento mais empreendedor.

\section{Referencial Teórico}

O referencial teórico contempla temáticas basilares para as posteriores análises, sendo: comportamento empreendedor e intenção empreendedora, ensino em Ciências Contábeis e educação empreendedora, motivação para aprender, e estudos assemelhados, detalhados a seguir.

\subsection{Comportamento Empreendedor e Intenção Empreendedora}

De maneira geral, o comportamento pode ser considerado como a forma com que os indivíduos procedem perante os estímulos e em relação ao seu entorno. Especificamente, o comportamento empreendedor pode ser descrito por características particulares que algumas pessoas apresentam frente às oportunidades, as quais evidenciam-se no modo de perceber, pensar e agir de forma empreendedora (Schaefer, 2018).

Entende-se que o comportamento empreendedor pode ser aprendido (Krüger et al., 2019). Neste sentido, Krüger (2019) destaca que uma das maneiras de se desenvolver o comportamento empreendedor é por meio de uma educação norteada para o empreendedorismo. Sendo que para aprender a empreender é necessário um comportamento proativo do indivíduo, o qual é mais bem previsto pela intenção empreendedora (Liñán, Rodríguez-Cohard \& Rueda-Cantuche, 2011).

A intenção empreendedora compreende o esforço e o estímulo que os indivíduos empregam para realizar o comportamento empreendedor em condições favoráveis (Cantner, Goethner \& Silbereisen, 2017; Souza, Santos, Lima, Cruz, \& Lezana, 2016). As intenções são influenciadas por diversos fatores, ainda que sejam tomadas de maneira voluntária e consciente (Hecke, 2011). Compreender as intenções mostrase particularmente valioso quando o fenômeno focal é raro, obscuro ou envolve atrasos imprevisíveis de tempo - um fenômeno focal como o empreendedorismo (Krueger, Reilly \& Carsrud, 2000). Sendo assim, a intenção empreendedora tem subsidiado a investigação de fatores cognitivos que podem motivar o indivíduo a empreender (Fayolle \& Liñán, 2014; Krueger, 2017; Paiva, Andrade, Antonialli, \& Brito, 2018). 
Dentre as diferentes teorias voltadas para a intenção destaca-se a Teoria do Comportamento Planejado (TCP) (Santos, Moura \& Almeida, 2018). A TCP identifica três antecedentes atitudinais da intenção que influenciam o comportamento (Ajzen, 1991). Visto que a TCP busca prever e explicar o comportamento humano em ambientes específicos, é possível aplicar os fundamentos dessa teoria para prever e explicar o comportamento empreendedor, considerando a intenção de começar um empreendimento (Liñán \& Chen, 2009). Logo, a partir da TCP, Liñán e Chen (2009) desenvolveram um modelo de intenção empreendedora. A Figura 1 apresenta esse modelo.

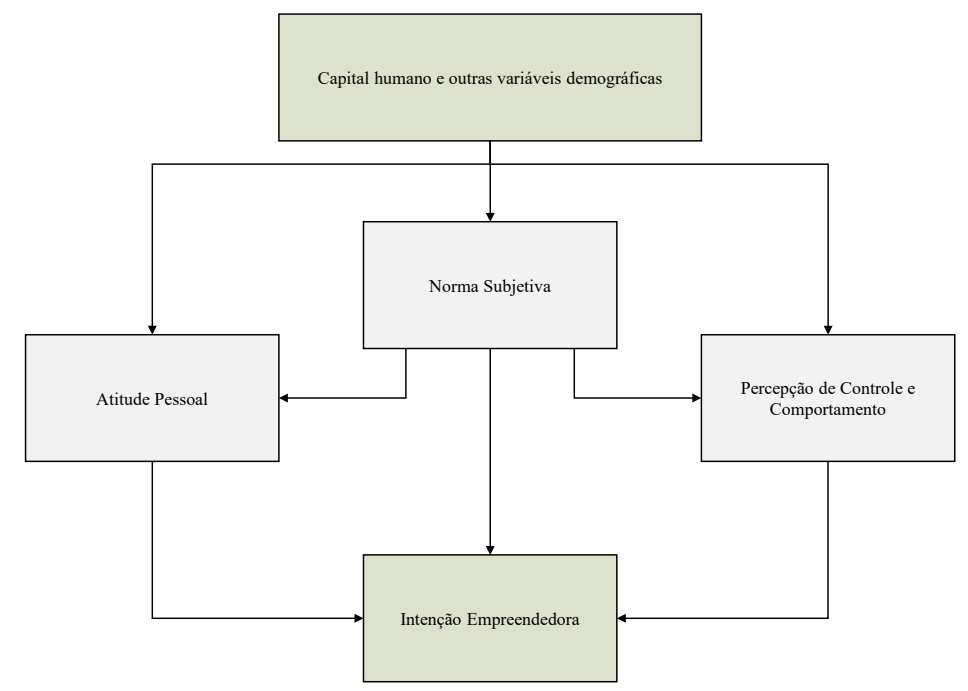

Figura 1. Modelo de intenção empreendedora

Fonte: adaptado de Liñán e Chen (2009, p. 597)

A partir da Figura 1, verifica-se que a primeira variável se refere à atitude face ao comportamento, ou seja, permite determinar o momento favorável para um determinado comportamento. A segunda variável corresponde às normas subjetivas, quer dizer a própria percepção que um indivíduo tem sobre a comunidade que o rodeia, determinando o seu comportamento.

Em seguida, a terceira variável reflete o grau de percepção de controle individual, levando o indivíduo a ter também um determinado comportamento. Dessa forma, tem-se que a formação de intenção empreendedora (IE) para realizar um comportamento é determinada por três variáveis independentes: a atitude pessoal (AP), as normas subjetivas (NS) e o controle comportamental percebido (PC), em que a relação entre esses três elementos e a intenção crescem proporcionalmente, e que, por sua vez, preveem o comportamento (Ajzein, 1991).

Diversos estudos sobre intenção empreendedora foram realizados (Hecke, 2011; Liñán \& Chen, 2009; Loiola, Gondimi, Pereira, \& Ferreira, 2016; Mirjana, Ana \& Marjana, 2018; Vieira \& Rodrigues, 2014), dentre eles destaca-se o estudo de Silva et al. (2019). Os autores concluíram que, de maneira geral, os estudantes de Ciências Contábeis têm baixa intenção em empreender. Os acadêmicos que estavam trabalhando, estavam matriculados no período noturno e que já haviam cursado disciplinas ou capacitações relacionadas ao empreendedorismo apresentaram uma intenção em empreender mais elevada em relação aos demais.

Diante disso, cabe destacar uma breve revisão da literatura sobre o ensino em Ciências Contábeis e a educação empreendedora. 


\subsection{Ensino em Ciências Contábeis e Educação Empreendedora}

A educação contábil é a atividade que ensina o uso dos caminhos, métodos e técnicas (Özpeynirc, Yücenurşen, Apakc, \& Polatc, 2015). Além de fazer com que os indivíduos adquiram essas habilidades ao longo de suas vidas profissionais, a educação contábil tem por essência o conceito de aprendizado contínuo para os sujeitos, por meio do qual esses indivíduos podem ser suficientes para atender às expectativas, seguindo o atual desenvolvimento e atualização dos níveis de conhecimento (Özpeynirci et al., 2015).

As técnicas as quais os educadores usam para ensinar os conteúdos de contabilidade nos cursos de graduação são variadas, dentre elas estão os usuais trabalhos em grupos e seminários, que auxiliam a desenvolver habilidades de comunicação (Souza, Avelar, Boina, \& Rodrigues, 2009). Marion (1996) expõe que o ensino contábil, em sua maioria, destaca somente os aspectos técnicos da profissão, como o aprendizado da escrituração, o que leva o aluno a crer que a profissão se restringe a operações rotineiras e cheias de detalhes, desfocando a importância da contabilidade na utilização das informações contidas nos relatórios contábeis, as quais auxiliam no processo de tomada de decisão. Neste sentido, Beck e Rausch (2015) salientam que a área contábil começa a exigir melhores e aprofundadas análises e discussões para se conhecer a sua realidade, sendo necessário um ensino capaz de formar profissionais competentes e atuantes.

Diante disso, observa-se que há uma certa necessidade do desenvolvimento do ensino em Ciências Contábeis voltado ao empreendedorismo. De acordo com Iwu et al. (2019), a educação empreendedora, além de ensinar os alunos sobre como iniciar e administrar um negócio, também promove o pensamento criativo, a inovação, o senso de autoestima e disciplina e também busca preparar os graduados para serem empreendedores e contribuírem para o desenvolvimento sustentável de sua economia.

Esses autores revelam que a educação para o empreendedorismo permite a aquisição de conhecimentos, atitudes, habilidades e comportamentos empreendedores (Iwu et al. 2019). Na mesma perspectiva, Jena (2020) afirma que a educação para o empreendedorismo incentiva as normas subjetivas dos alunos, bem como suas intenções em relação ao empreendedorismo, aprimorando a habilidade e o conhecimento dos estudantes. Diante disso, a educação para o empreendedorismo na área contábil é vista como um meio eficaz de preparar os graduados para a transição da universidade para o mercado de trabalho (Reyad, Al-Sartawi, Badawi, \& Hamdan, 2019). Para esses autores, a ênfase não está apenas na aquisição de conhecimento, mas também no desenvolvimento de habilidades e competências.

A partir da relevância do fomento de um comportamento em prol do empreendedorismo na formação profissional do contador e diante da lacuna do estudo de Silva et al. (2019), nesta pesquisa direcionou-se para a intenção empreendedora dos acadêmicos de Ciências Contábeis e sua relação com a motivação para aprender. Adiante detalha-se a temática de motivação.

\subsubsection{Motivação para Aprender}

No que diz respeito ao resultado da aprendizagem, pesquisas demonstraram que a capacidade de identificar, assimilar e aplicar o conhecimento adquirido e a motivação para aprender dos alunos são fatores essenciais (Tho, 2017). No contexto do aprendizado, a motivação é conceituada como uma fonte interna que melhora, mantém ou medeia o desenvolvimento cognitivo (Barak, Watted, \& Haick, 2016).

A motivação e o processo de aprendizagem têm uma profunda conexão, sendo a motivação, o núcleo das aspirações do ser humano e das realizações. Assim, a motivação é crucial para se ter sucesso em questões educacionais e sem o espírito de luta nada é possível não apenas na educação, mas também na vida real (Gopalan et al., 2017). A motivação para aprender influencia os processos de tomada de decisão em relação a direção, foco e nível de esforço aplicado a uma atividade de aprendizagem (Cole, Harris \& Feild, 2004). 
Neste sentido, Nguyen e Nguyen (2010) destacam que a motivação para aprender aprimora o conhecimento e as habilidades adquiridas pelos alunos, pois alunos com alta motivação para aprender terão estratégias mais eficazes para a aprendizagem e maiores níveis de comprometimento com o acúmulo de conhecimentos e habilidades.

Há varias teorias sobre motivação para aprender, salienta-se que as teorias cognitivas da motivação para a aprendizagem dão preferência ao estudo das crenças, valores e emoções do sujeito, por considerarem que essas desempenham um efeito mediador no comportamento e mostram-se como uma forte influência no processo motivacional (Lourenço, \& Paiva, 2010). Diante disso, insere-se a TCP de Ajzen (1991) e a intenção empreendedora de Liñán e Chen (2009). Dessa forma, conforme abordagem teórica discorrida este estudo visa testar a seguinte hipótese:

\section{$H_{1}$ : Existe relação significativa positiva entre intenção empreendedora e motivação para aprender dos estudantes de Ciências Contábeis da UFSM.}

\subsection{Estudos Assemelhados}

Nesta seção, são apresentados estudos assemelhados com a pesquisa ora realizada, no intuito de servir de base para um maior entendimento sobre os constructos estudados, bem como subsidiar as posteriores análises e discussões.

O modelo de de Liñán e Chen (2009) foi validado no Brasil por Hecke (2011). Em seu estudo, a autora aplica o modelo aos graduandos de Administração e Ciências Contábeis de Curitiba. O estudo objetivou verificar se há diferença nas intenções empreendedoras dos alunos pesquisados. Quanto aos resultados, a autora aponta que há necessidade de uma maior inclusão de disciplinas voltadas ao desenvolvimento da intenção empreendedora dos alunos.

Loiola et al. (2016) analisaram o efeito de variáveis de percepção de contexto do ambiente universitário e familiar, e o efeito de variáveis motivacionais e atitudinais na intenção empreendedora de jovens universitários. Participaram da pesquisa aproximadamente três mil estudantes. Como resultados os autores elucidaram que a motivação para aprender é o melhor influenciador da intenção empreendedora, seguida da aprendizagem empreendedora e, em menor grau, da percepção de risco (Loiola et al., 2016).

Os determinantes das intenções empreendedoras por meio da TCP foram examinados por Mirjana, Ana e Marjana (2018), em graduandos da Eslovênia. O estudo objetivou explorar o efeito de atitudes pessoais em relação ao empreendedorismo, normas subjetivas e controle comportamental percebido, como três antecedentes de intenção reconhecidos pela TCP, nas intenções empreendedoras. Os resultados obtidos revelaram que as intenções empreendedoras de um indivíduo estão positivamente relacionadas a atitudes pessoais em relação ao comportamento empreendedor, normas subjetivas impostas pelo ambiente externo e controle comportamental percebido. Para os autores, estes antecedentes motivacionais podem ser vistos como bons preditores da intenção empreendedora.

Para os estudantes de graduação em Ciências Contábeis, Silva et al. (2019) analisaram a intenção empreendedora desses alunos, em uma universidade federal brasileira. Os autores concluíram que, de maneira geral, os respondentes têm baixa intenção em empreender. Os acadêmicos que estavam trabalhando, estavam matriculados no período noturno e que já haviam cursado disciplinas relacionadas ao empreendedorismo apresentaram uma intenção em empreender mais elevada em relação aos demais.

Recentemente, Krüger, Borré, Lopes e Michelin (2021) analisaram a relação entre os construtos do comportamento planejado e as lideranças, transformacional e transacional, em graduandos de Ciências Contábeis. Os resultados não demonstraram correlação significativa entre intenção empreendedora e as lideranças analisadas. 
A partir da lacuna do estudo de Silva et al. (2019), esta pesquisa direcionou-se para acadêmicos de Ciências Contábeis e sua relação com a motivação para aprender. Encerrando o referencial teórico, a seguir detalha-se a metodologia deste estudo.

\section{Metodologia}

Para a realização deste estudo, conforme o objetivo estabelecido, a pesquisa é classificada como quantitativa, quanto à abordagem do problema; descritiva, quanto aos objetivos; e de levantamento (survey), quanto aos procedimentos técnicos. Na obtenção dos dados, utilizou-se um questionário composto de cinco blocos de assertivas, a saber: Motivação para Aprender (MA), Atitudes Pessoais (AP), Normas Subjetivas (NS), Percepção de Controle Comportamental (PC) e Intenção Empreendedora (IE).

Com base nisso, para mensurar a MA, utilizou-se o constructo de Tho (2017), sendo composto de 5 afirmações. Enquanto que para medir a IE, utilizou-se o Questionário de Intenção Empreendedora (QIE) (Liñán \& Chen, 2009), previamente validado no Brasil (Hecke, 2011). O QIE foi desenvolvido para medir intenções e as demais variáveis que a influenciam, baseado na literatura teórica e empírica existente sobre a aplicação da TCP ao empreendedorismo (Liñán \& Chen, 2009).

O QIE é composto de quatro blocos de perguntas totalizando 22 assertivas, distribuídas em: AP, NS, PC e IE. Os três primeiros blocos de questões do QIE focam nas atitudes comportamentais dos estudantes, a respeito da percepção dos alunos com relação as atitudes pessoais. Enquanto o quarto bloco, refere-se à intenção empreendedora, ou seja, o foco dessas questões é capturar a percepção dos pesquisados quanto à intenção de empreender. O instrumento foi respondido pelos estudantes de acordo com uma escala tipo Likert de 7 pontos para MA (a escala variando de 1 (fortemente em desacordo) até 7 (concordo fortemente), e de 5 pontos para o QIE (com a seguinte gradação: $1=$ nunca, $2=$ raras vezes, 3 às vezes, $4=$ frequentemente e $5=$ sempre).

Além disso, inicialmente o aluno respondeu sete questões relacionadas a dados complementares de suporte, que se referem à matrícula, ao semestre, ao sexo, à idade, se trabalha, se já cursou alguma disciplina relacionada a empreendedorismo e se já exerceu ou tem alguém na família que exerce ou exerceu atividade empreendedora. Após a organização e impressão do instrumento de coleta, foram levantados os horários de aula e as respectivas turmas no intuito de limitar que um mesmo aluno respondesse ao questionário mais de uma vez.

A coleta dos dados ocorreu no mês de agosto de 2019, em Santa Maria, campus da UFSM. Os questionários foram aplicados em sala de aula, com permissão prévia do professor ministrante para cada turma visitada. Os alunos foram informados sobre o objetivo do estudo e, em seguida, solicitados a preencher, voluntariamente e de maneira anônima, o questionário. Sendo disponibilizado um período de tempo para que os interessados respondessem ao instrumento. Os questionários foram então recolhidos e posteriormente tabulados e analisados. Foram coletados 221 questionários.

Diante dos questionários coletados, dois deles foram retirados da amostra por terem sido respondidos de forma incompleta, restando 219 questionários considerados aptos à análise. Após o processo de tabulação e codificação dos dados, obtidos por meio dos questionários respondidos, realizado em uma planilha eletrônica do programa Microsoft Office Excel', realizou-se uma conferência, com o objetivo de verificar possíveis erros de digitação. Para tratamento e análise dos dados coletados procederam-se testes estatísticos, utilizando o software Statistical Packagefor the Social Sciences (SPSS $)$, nessa ocasião os dados foram analisados quantitativamente e explorados com base nos modelos de Liñán e Chen (2009) e Tho (2017). 
Para cada um dos constructos pesquisados, calcularam-se os mínimos, máximos, médias, desvio-padrão e variância de cada assertiva. Para o tratamento e a análise dos resultados das variáveis representativas da motivação para aprender e da intenção empreendedora, considerou-se uma padronização da escala em escala de razão de 0 a 100\%, os quais são convencionados em três categorias: Baixo (para média de 0 a 33,33\%), Moderado (média entre 33,34\% a 66,66\%) e Alto (média de 66,67\% a 100\%) nível comportamental (Lopes, 2016).

Em seguida, para estimar a confiabilidade foi medida a consistência interna por meio do Coeficiente Alfa de Cronbach (Sampieri, Collado, \& Lucio, 2013). Com a finalidade de estabelecer a associação entre os constructos de motivação para aprender e intenção empreendedora dos alunos, bem como das respectivas variáveis, utilizou-se o Coeficiente de Correlação de Spearman, que tem como objetivo descobrir associações entre duas ou mais variáveis, identificando e esclarecendo as variáveis cujas relações vão ser exploradas (Moreira \& Caleffe, 2008). Foi realizada a Correlação de Spearman, tendo em vista a não normalidade dos dados auferida pelos testes Shapiro-Wilk e Kolmogorov-Smirnov. Para a interpretação das correlações, foi adotada a seguinte classificação dos coeficientes de correlação: coeficientes de correlação $<0,4$ (correlação fraca), >0,4 a <0,5 (correlação moderada) e >0,5 (correlação forte) (Hulley et al., 2003).

Adiante, realizou-se o relacionamento entre os constructos de motivação para aprender e intenção empreendedora por meio de regressão. O teste estatístico de regressão explica a variabilidade de uma variável, chamada dependente, pelas variabilidades de outras variáveis, chamadas independentes (Becker, 2015). Tendo o objetivo de "prever uma única variável dependente a partir do conhecimento de uma ou mais variáveis independentes" (Hair Jr., Black, Babin, Anderson, \& Tatham, 2009, p. 154). A partir do detalhamento do tratamento dos dados desta pesquisa, a seguir apresentam-se a análise e discussão dos resultados.

\section{Análise e Discussão dos Resultados}

A presente análise e discussão dos resultados é segregada com base nos objetivos específicos estabelecidos. Inicialmente, apresenta-se o perfil dos alunos pesquisados. Em seguida, consta a estatística descritiva para os constructos pesquisados e a confiabilidade para o instrumento e constructos. Posteriormente, correlacionou-se os constructos do QIE e da MA. Por fim, por meio de regressão, determinou-se a influência da IE na MA, analisando a relação entre IE e MA. Tais resultados são apresentados e discutidos a seguir.

\subsection{Perfil dos Alunos de Ciências Contábeis}

A amostra pesquisada é composta de 219 alunos do curso de Ciências Contábeis (UFSM), dos turnos diurno e noturno. Os respondentes se encontravam devidamente matriculados, distribuídos do primeiro ao décimo semestre. Observou-se que ao longo dos semestres ocorre uma redução na quantidade de alunos (Tabela 1), isso é motivado pela desistência do curso, reprovação ou alteração de turno (geralmente para o noturno), o que faz com que ocorra uma diminuição na quantidade de alunos por turma. Essa redução é reforçada por Silva et al. (2020), que concluíram que 31\% dos alunos dos cursos de Ciências Contábeis no Brasil evadem. 
A situação entre o vínculo empregatício (trabalho) e o respectivo turno que estão matriculados são detalhados na Tabela 1.

Tabela 1

Alunos por semestre e relação entre trabalho e turno que estão matriculados

\begin{tabular}{|c|c|c|c|c|c|c|c|c|c|c|c|}
\hline Semestre & $1^{\circ}$ & $2^{\circ}$ & $3^{\circ}$ & $4^{\circ}$ & $5^{\circ}$ & $6^{\circ}$ & $7^{\circ}$ & $8^{\circ}$ & $9^{\circ}$ & $10^{\circ}$ & Total \\
\hline \multirow{2}{*}{$\begin{array}{c}\mathrm{N}^{\circ} \text { Respondente } \\
\%\end{array}$} & 32 & 26 & 21 & 22 & 18 & 23 & 13 & 25 & 24 & 15 & 219 \\
\hline & $15 \%$ & $12 \%$ & $10 \%$ & $10 \%$ & $9 \%$ & $10 \%$ & $6 \%$ & $11 \%$ & $11 \%$ & $7 \%$ & $100 \%$ \\
\hline \multirow{2}{*}{ Turno } & \multicolumn{3}{|c|}{ Trabalham } & \multicolumn{4}{|c|}{ Não trabalham } & \multicolumn{4}{|c|}{ Total por turno } \\
\hline & \multicolumn{2}{|c|}{ Quantidade } & $\%$ & \multicolumn{2}{|c|}{ Quantidade } & \multicolumn{2}{|c|}{$\%$} & \multicolumn{2}{|c|}{ Quantidade } & \multicolumn{2}{|c|}{$\%$} \\
\hline Diurno & \multicolumn{2}{|c|}{26} & $24,8 \%$ & \multicolumn{2}{|c|}{61} & \multicolumn{2}{|c|}{$55 \%$} & \multicolumn{2}{|c|}{87} & \multicolumn{2}{|c|}{$40,3 \%$} \\
\hline Noturno & \multicolumn{2}{|c|}{79} & $75,2 \%$ & \multicolumn{2}{|c|}{50} & \multicolumn{2}{|c|}{$45 \%$} & \multicolumn{2}{|c|}{129} & \multicolumn{2}{|c|}{59,7} \\
\hline Total & \multicolumn{2}{|c|}{105} & $100 \%$ & \multicolumn{2}{|c|}{111} & \multicolumn{2}{|c|}{$100 \%$} & \multicolumn{2}{|c|}{216} & \multicolumn{2}{|c|}{$100 \%$} \\
\hline
\end{tabular}

Fonte: elaborado pelos autores.

A partir da Tabela 1, observa-se que a maioria dos respondentes estudam no turno noturno (aproximadamente 60\%). Em relação ao vínculo empregatício, destaca-se que a maioria dos respondentes não trabalha (51,4\%). Aprofundando a análise quanto ao turno e o vínculo empregatício, constata-se que, dos alunos do noturno, 79 (75,2\%) dos respondentes possuem algum tipo de vínculo empregatício. Resultado contrário foi obtido no turno diurno, no qual a maioria ( $\cong 55 \%)$ não trabalha (Tabela 1$)$. Esses resultados podem demonstrar que o curso na modalidade noturno possibilita ao acadêmico trabalhar o dia todo, ampliando as alternativas de emprego. Atenta-se que 3 alunos não responderam às questões sobre turno e trabalho.

Em relação ao sexo, entre os respondentes, aproximadamente, 52\% (113 alunos) são do sexo masculino e $48 \%$ (106) correspondem ao sexo feminino. No que se refere à faixa etária, a maioria dos estudantes respondeu possuir entre 18 e 23 anos (56,6\%, 124 alunos), seguido de 24 a 29 anos (21\%, 46 alunos). Esse resultado evidencia que os estudantes de Ciências Contábeis pesquisados são, na maioria, jovens, recém-formados do ensino médio.

Em seguida, apurou-se se os acadêmicos já haviam cursado alguma disciplina ou curso de curta duração relacionado ao empreendedorismo. A maioria dos respondentes informou que não cursou disciplina sobre empreendedorismo, o que corresponde à aproximadamente $66 \%$ da amostra pesquisada (145 estudantes). Ao final do bloco de caracterização, o estudante foi questionado se o respondente ou algum membro de sua família exerce ou, em algum momento, exerceu atividades empreendedoras. Dentre os 219 respondentes, 131 afirmaram que sim, o que corresponde a aproximadamente $60 \%$ da amostra pesquisada.

De modo geral, a amostra pesquisada corresponde a alunos do sexo masculino, entre 18 e 23 anos de idade, que estudam no turno noturno, que não trabalham, que nunca cursaram disciplina relacionada ao empreendedorismo e que já exerceram, ou alguém da família já exerceu, atividades empreendedoras. Diante dessa caracterização do perfil dos pesquisados, a seguir apresenta-se a estatística descritiva e a confiabilidade da pesquisa. 


\subsection{Estatística Descritiva e Confiabilidade}

A Tabela 2 demonstra a estatística descritiva para os alunos pesquisados, a fim de analisar cada uma das dimensões previstas nos modelos originais, sendo MA, AP, NS, PC e IE.

Tabela 2

\section{Estatística descritiva}

\begin{tabular}{|c|c|c|c|c|c|c|c|c|}
\hline \multirow[t]{2}{*}{ Co. } & \multirow{2}{*}{$\begin{array}{c}\text { Items } \\
\text { General }\end{array}$} & \multirow{2}{*}{$\frac{\text { Mínimo }}{5,00}$} & \multirow{2}{*}{$\frac{\text { Máximo }}{35,00}$} & \multirow{2}{*}{$\frac{\text { Média }}{23,4703}$} & \multicolumn{2}{|c|}{ Razão } & \multirow{2}{*}{$\frac{\text { Desvio-Padrão }}{6,07392}$} & \multirow{2}{*}{$\frac{\text { Variância }}{36,892}$} \\
\hline & & & & & 66,09 & Moderada & & \\
\hline \multirow[t]{3}{*}{ ML } & Male & 6,00 & 35,00 & 22,0708 & 61,97 & Moderada & 6,15386 & 37,870 \\
\hline & Female & 5,00 & 35,00 & 25,0476 & 70,73 & Alta & 5,60113 & 31,373 \\
\hline & General & 5,00 & 25,00 & 18,0776 & 71,16 & Alta & 4,64308 & 21,558 \\
\hline \multirow[t]{3}{*}{ PA } & Male & 7,00 & 25,00 & 18,5841 & 73,27 & Alta & 4,68799 & 21,977 \\
\hline & Female & 5,00 & 25,00 & 17,4857 & 68,69 & Alta & 5,00 & 25,00 \\
\hline & General & 5,00 & 25,00 & 18,9178 & 74,66 & Alta & 4,18852 & 17,544 \\
\hline \multirow[t]{3}{*}{ SN } & Male & 5,00 & 25,00 & 18,8584 & 74,41 & Alta & 4,55496 & 20,748 \\
\hline & Female & 5,00 & 25,00 & 19,0381 & 75,16 & Alta & 3,75173 & 14,075 \\
\hline & General & 6,00 & 30,00 & 16,6895 & 54,10 & Moderada & 5,38725 & 29,022 \\
\hline \multirow[t]{3}{*}{ PBC } & Male & 6,00 & 30,00 & 16,8850 & 54,78 & Moderada & 5,16297 & 26,656 \\
\hline & Female & 6,00 & 30,00 & 16,3333 & 52,87 & Moderada & 5,45729 & 29,782 \\
\hline & General & 6,00 & 30,00 & 17,3151 & 56,26 & Moderada & 6,91271 & 47,786 \\
\hline \multirow[t]{2}{*}{ El } & Male & 6,00 & 30,00 & 18,1150 & 59,02 & Moderada & 6,97541 & 48,656 \\
\hline & Female & 6,00 & 30,00 & 16,3905 & 53,07 & Moderada & 6,76600 & 45,779 \\
\hline
\end{tabular}

Legenda: Co. = Constructo, Masc. = Masculino, Femi. $=$ Feminino.

N válido: Geral 219, Masc. 113, Femi. 106.

Fonte: elaborado pelos autores.

Por meio da Tabela 2, nota-se que para o constructo de MA o mínimo foi de 5 e o máximo de 35 pontos. Para os constructos de AP e NS o mínimo foi de 5 e o máximo de 25 pontos, enquanto que para os constructos de PC e IE o mínimo foi de 6 e o máximo foi de 30 pontos. Essa diferença nos mínimos e máximos dos constructos de motivação e intenção deve-se à diferente pontuação da escala Likert e da quantidade de variáveis para cada constructo.

A partir da análise da Tabela 2 percebe-se que o constructo de NS apresentou menor valor para desvio-padrão e variância frente aos demais, demonstrando uniformidade nas respostas. O oposto ocorreu para IE, que obteve maior desvio-padrão e variância entre as respostas, por meio da qual entende-se que os estudantes não são unânimes quanto à intenção de empreender, o que é reforçado pela média de pontuação, estando entre as mais baixas, juntamente com PC.

Em relação ao sexo, comparando homens e mulheres, constata-se que as mulheres apresentam razão alta quanto à motivação para aprender, em contrapartida da razão moderada desse constructo para os homens. Esse resultado é suportado por Porto e Gonçalves (2017), que também constataram que as mulheres têm maior motivação e envolvimento acadêmico do que os homens.

Para AP e NS ambos sexos constam com razão alta. Cabe destacar que os homens apresentaram maior média para AP (avaliação pessoal em relação a empreender), enquanto as mulheres revelaram média maior para NS (sofrem mais influência das pessoas de referência, como pais, irmãos e cônjuge). Já PC e IE denotam razões moderadas, sendo que os homens demonstraram média superior para ambos os constructos, o que significa que têm maior pretensão para empreender e acreditam no seu potencial (Liñán \& Chen, 2009). 
Para que fosse estimada a confiabilidade das respostas do instrumento aplicado, foi apurado o Alfa de Cronbach. Neste estudo, obteve-se Alfa de Cronbach geral de $\alpha=0,914$, significando que os valores resultantes da aplicação do questionário são confiáveis. Além disso, apurou-se os valores de confiabilidade para cada constructo analisado, sendo: MA (,866), AP (,896), NS (,778), PC (,903) e IE (,955). Observase que todos os constructos apresentaram valores aceitáveis, maiores que 0,7 , concluindo-se que são confiáveis, pois apresentam uma boa consistência interna. Em seguida verificou-se as pontuações quanto ao vínculo empregatício e os constructos do QIE e MA, apresentados na Figura 2.

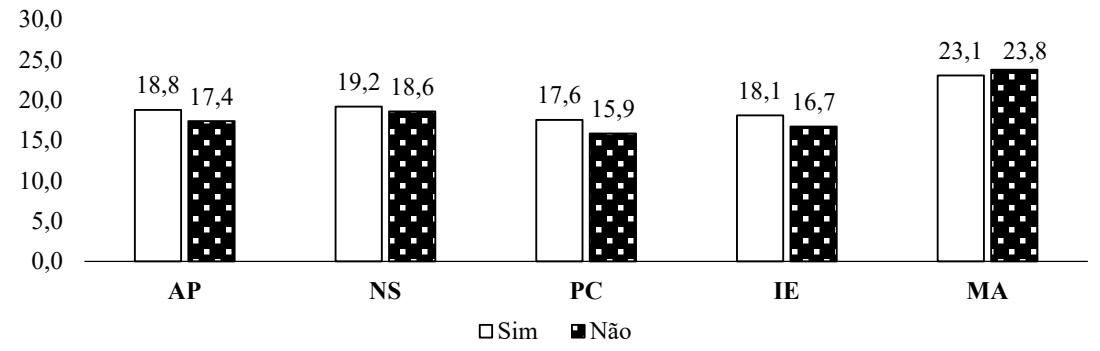

Figura 2. Experiência profissional por constructo

Fonte: elaborado pelos autores.

A partir da Figura 2, percebe-se que os alunos que trabalham têm intenção de empreender maior do que os alunos que não trabalham, para Silva et al. (2019) essa diferença é justificada devido à experiência profissional angariada. Krueger et al. (2000) corroboram tal percepção, para esses autores as intenções empreendedoras podem ser estimuladas pela experiência profissional prévia. Em contraponto, a MA nos estudantes que trabalham se mostrou menor do que para aqueles que não trabalham, o que pode ser justificado pelo fato de que o estudante que não trabalha tem mais tempo para se dedicar aos estudos interferindo na sua motivação para aprender.

Logo, a escassez de tempo para o estudante que trabalha pode interferir na sua MA. Na amostra pesquisada, verifica-se que a maioria dos alunos que trabalham estudam no turno noturno, sinalizando que trabalham no turno inverso às aulas, limitando o tempo para se dedicar aos estudos. Posteriormente, comparou-se as pontuações dos estudantes que afirmaram terem cursado alguma disciplina voltada ao empreendedorismo versus os que não cursaram, quanto aos constructos do QIE e MA. Tais resultados são apresentados na Figura 3.

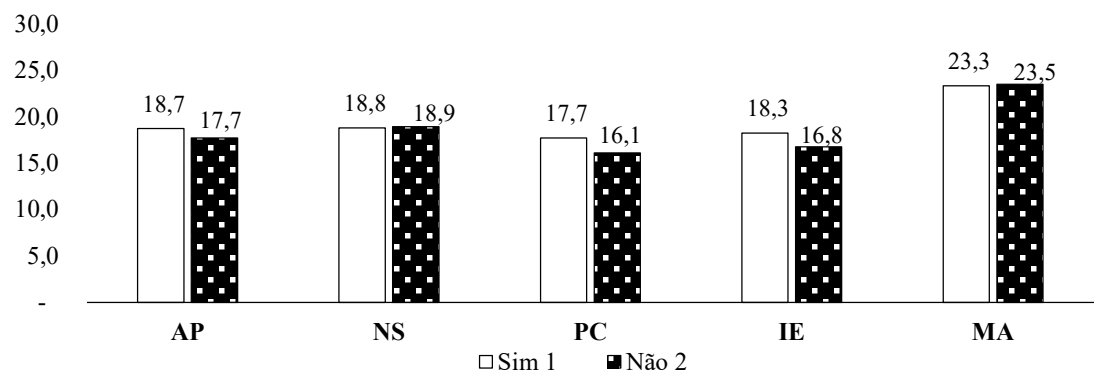

Figura 3. Conhecimento sobre empreendedorismo por constructo

Fonte: elaborado pelos autores. 
Um maior conhecimento dos diferentes aspectos do empreendedorismo pode contribuir para percepções mais realistas sobre a atividade empreendedora, influenciando indiretamente nas intenções (Liñán \& Chen, 2009). Neste sentido, conforme demonstra a Figura 3, o conhecimento sobre empreendedorismo obteve pontuações maiores nos constructos de AP, PC e IE, ou seja, os alunos com algum conhecimento em empreendedorismo tendem a ter uma inclinação maior para empreender, considerando essas três dimensões.

Tais dimensões têm relação com a conveniência pessoal e facilidade ou dificuldade de se tornar um empreendedor (Liñán \& Chen, 2009). Em estudo anterior, Silva et al. (2019) evidenciaram que os acadêmicos que haviam cursado alguma disciplina voltada ao empreendedorismo apresentaram um comportamento mais direcionado ao empreendedorismo, corroborando aos achados deste estudo.

Salienta-se que tal diferença não foi verificada para a dimensão de NS, que obteve resultado inferior para aqueles que afirmaram ter cursado alguma disciplina/capacitação voltada ao empreendedorismo (Figura 3). Essa dimensão é considerada um fator extrínseco, pois corresponde à pressão social percebida pelo estudante em realizar ou não um comportamento em consonância à percepção sobre o que as pessoas importantes de sua vida poderiam pensar acerca da decisão tomada (Liñán et al., 2011). Do mesmo modo, para MA o conhecimento prévio em/sobre empreendedorismo não evidenciou maior pontuação frente os estudantes sem esse conhecimento. Assim, percebe-se que ter cursado disciplina ou curso sobre empreendedorismo não demonstra maiores médias para NS e MA. A seguir, correlacionam-se os constructos pesquisados.

\subsection{Associação entre Intenção Empreendedora e Motivação para Aprender}

Para mensurar a associação entre os constructos, utilizou-se a análise de Correlação de Spearman, tendo em vista a não normalidade dos dados. Para este estudo, adotou-se a conversão de Hulley et al. (2003), na qual coeficientes de correlação $<0,4$ apresentam correlação fraca, valores de $>0,4$ a $<0,5$ demonstram correlação moderada, e, correlações $>0,5$ revelam uma correlação forte. Na Tabela 3, constam as associações para os constructos de MA e do QIE.

Tabela 3

\section{Correlação para os constructos}

\begin{tabular}{lccccc}
\hline & MA & AP & NS & PC & IE \\
\cline { 2 - 6 } MA & $\mathbf{1}$ & & & & \\
AP &, 055 & $\mathbf{1}$ & & & \\
NS &, 087 &, $269^{* *}$ & $\mathbf{1}$ & & \\
PC &, 014 &, $574^{* *}$ &, $297^{* *}$ & $\mathbf{1}$ & $\mathbf{1}$ \\
IE &, 079 &, $789^{* *}$ &, $232^{* *}$ &, $646^{* *}$ & $\mathbf{1}$ \\
\hline
\end{tabular}

** A correlação é significativa no nível 0,01 (bilateral). N válido (listwise) 219.

Fonte: elaborado pelos autores.

Diante dos valores apresentados na Tabela 3, infere-se que a associação entre os constructos do QIE e MA não apresentou correlação significativa. A motivação para aprender pode ser entendida como um desejo por parte dos alunos de aprender o conteúdo estabelecido no programa de ensino, assim, alunos com níveis mais altos de MA são mais inclinados a buscar estratégias de aprendizagem mais eficazes que facilitam a aquisição de conhecimento (Tho, 2017), o que poderia estar associado a aspectos do QIE, como AP, PC, NS ou IE.

No entanto, houve correlações significativas a 1\%, logo, existem $99 \%$ de chances de associação apenas entre as dimensões do QIE. A dimensão de AP, que explora as percepções sobre a conveniência pessoal de ser empreendedor (Liñán \& Chen, 2009), apresentou diferentes níveis de correlação com os demais constructos. 
A associação com NS, que se refere à percepção de que as "pessoas de referência" apoiariam ou não a decisão de se tornar um empreendedor (Ajzen, 2001), apresentou correlação classificada como fraca $(0,269)$. Enquanto que a correlação de AP com PC $(0,575)$, que corresponde a autopercepção da facilidade ou dificuldade de se tornar um empreendedor (Liñán \& Chen, 2009), e de AP com IE $(0,789)$, que indica o esforço despendido para a realização do comportamento empreendedor (Liñán \& Chen, 2009), apresentaram correlações fortes (Hulley et al., 2003).

Os constructos de NS, PC e IE, com base na classificação de Hulley et al. (2003), estão fracamente relacionadas uns com os outros, sendo NS com PC $(0,297)$ e NS com IE $(0,232)$. Liñán e Chen (2009) salientam que NS exerceria certa influência na AP e no PC, os autores argumentam que quando os indivíduos sentem que as "pessoas de referência" os apoiariam na decisão de se tornarem empreendedores eles se sentiriam mais capazes de executá-la de maneira satisfatória. Enquanto que PC e IE $(0,646)$ demonstram uma correlação forte (Hulley et al., 2003).

Estes resultados se assemelham aos encontrados por Silva et al. (2019), que pesquisaram as dimensões do QIE nos alunos de Ciências Contábeis da UFSM em 2018. Para os autores, a associação da AP e IE demonstrou haver influencia forte e positiva, enquanto que a associação dos constructos NS e IE se correlacionaram de maneira fraca.

Por meio da correlação, verificou-se que não houve associação significativa entre os constructos do QIE e MA. Por conseguinte, apresenta-se a análise de regressão, tida como uma extensão da análise da correlação, que objetiva analisar a previsibilidade e explicação das variáveis pesquisadas a partir da definição da variável dependente e das variáveis independentes (Hair Jr. et al., 2009).

\subsection{Relação entre Intenção Empreendedora e Motivação para Aprender}

Neste subcapítulo, apresenta-se uma análise estatística com base em regressão, que é uma técnica estatística que permite explorar a relação entre uma variável dependente e uma variável independente (regressão simples) ou com várias variáveis independentes (regressão múltipla) (Hair Jr. et al., 2009), de modo a identificar a significância das variáveis explicativas, na qual buscou-se relacionar as dimensões e as variáveis pesquisadas, quais sejam: Perfil, QIE e MA.

Inicialmente, analisou-se a regressão com todas as dimensões somadas (AP, NS, PC, IE) formando um único indicador (QIE) relacionado à MA (variável dependente). Ao analisar a qualidade do modelo de regressão por meio do $\mathrm{R}^{2}$ (Coeficiente de determinação), para o modelo de MA, percebe-se um resultado baixo $(, 013)$, o que significa que o modelo apresenta baixo poder explicativo.

$\mathrm{O} \mathrm{R}^{2}$ ajustado (Coeficiente ajustado de determinação) considera o número de variáveis independentes incluídas na equação de regressão e o tamanho da amostra (Hair Jr. et al., 2009). Com base nisso, salienta-se que o $R^{2}$ ajustado apresentou redução frente ao coeficiente de determinação $\left(R^{2}\right)$, o que pode ser explicado pela inclusão de variáveis que apresentaram pouco poder de explicação ou previsão. Já o erro padrão da estimativa $\left(\mathrm{SE}_{\mathrm{E}}\right)$ trata da distribuição esperada de valores previstos que ocorreriam se fossem tomadas múltiplas amostras dos dados (Hair Jr. et al., 2009).

Por conseguinte, na Tabela 4, são apresentados os coeficientes para o modelo de MA.

Coeficientes do modelo de MA

\begin{tabular}{|c|c|c|c|c|c|c|}
\hline \multirow{2}{*}{\multicolumn{2}{|c|}{ Modelo }} & \multicolumn{2}{|c|}{ Coef. não padronizados } & \multirow{2}{*}{$\begin{array}{c}\begin{array}{c}\text { Coef. } \\
\text { padronizados }\end{array} \\
\text { Beta } \\
\end{array}$} & \multirow[t]{2}{*}{$\mathrm{t}$} & \multirow[t]{2}{*}{ Sig } \\
\hline & & B & Erro Padrão & & & \\
\hline \multirow{2}{*}{ MA } & (Constante) & 16,649 & 1,408 & & 11,828 & ,000 \\
\hline & QIE & ,039 & ,023 & ,113 & 1,672 & ,096 \\
\hline
\end{tabular}

Fonte: elaborado pelos autores. 
Quando todas as variáveis de uma regressão estão padronizadas (Coeficientes padronizados), o Beta assume um valor 0 (Tabela 4), o que permite ao pesquisador comparar diretamente o efeito relativo de cada variável independente sobre a variável dependente $(, 113)$. Por meio dos coeficientes, percebe-se correlação positiva entre as variáveis pesquisadas (Tabela 4). Enquanto que o Teste té um teste estatístico da contribuição adicional de uma variável para a precisão de previsão acima da contribuição das variáveis que já constam na equação (Hair Jr. et al., 2009) (Tabela 4). Essa regressão evidencia que o QIE apresenta relação significativa a $10 \%$ com MA, ou seja, existe $90 \%$ de chance de o QIE (AP, NS, PC e IE juntos) influenciar a MA.

Para melhor compreender este primeiro resultado, analisou-se a relação entre cada dimensão do QIE (AP, NS, PC e IE) e as variáveis de perfil, variáveis explicativas, com MA (variável dependente). Inicialmente, verificou-se a relação da dimensão AP e as variáveis de perfil (independentes) em relação à variável dependente de MA. Para o perfil, foram inseridas as variáveis sexo, idade, se trabalha (Trabalha), se já cursou disciplina de empreendedorismo (CDiscEmpr), se exerce ou já exerceu atividade empreendedora (AtivEmpr) e semestre letivo (Semestre). No que diz respeito ao $\mathrm{R}^{2}$, o valor de, 084 demonstra baixa qualidade do modelo, o que corresponde a uma limitação da pesquisa. Em seguida, a Tabela 5 mostra os coeficientes do modelo para a dimensão $\mathrm{AP}$ e perfil com relação à MA.

Tabela 5

Coeficientes do modelo para a dimensão AP e perfil

\begin{tabular}{|c|c|c|c|c|c|c|}
\hline \multicolumn{2}{|c|}{ Modelo } & \multicolumn{2}{|c|}{ Coef. não padronizados } & \multirow{2}{*}{$\begin{array}{c}\begin{array}{c}\text { Coef. } \\
\text { padronizados }\end{array} \\
\text { Beta }\end{array}$} & \multirow[t]{2}{*}{$\mathrm{t}$} & \multirow[t]{2}{*}{ Sig } \\
\hline & & B & Erro Padrão & & & \\
\hline \multirow{8}{*}{ AP e Perfil } & (Constante) & 13,384 & 3,114 & & 4,298 & ,000 \\
\hline & Semestre &,- 136 & 143 &,- 074 &,- 954 & 341 \\
\hline & Sexo & 2,655 & 709 & ,266 & 3,743 &, 000 \\
\hline & Idade & ,232 & ,449 & ,039 &, 518 & 605 \\
\hline & Trabalha & , 101 & 744 & ,010 & ,136 & ,892 \\
\hline & CDiscEmpr & 027 & 788 & ,003 & 035 & ,972 \\
\hline & AtivEmpr &,- 350 & 743 &,- 034 &,- 470 & ,639 \\
\hline & AP & 129 & ,092 & 100 & 1,390 & 166 \\
\hline
\end{tabular}

Fonte: elaborado pelos autores.

A partir da Tabela 5, infere-se que o modelo para a dimensão AP e perfil não se mostrou significativo para prever MA, com exceção da variável sexo. Isso demonstra que essas variáveis, com exceção de sexo, não conseguem explicar, estatisticamente, a determinante MA. Destaca-se que a dimensão de AP referese ao grau em que o indivíduo detém de uma avaliação pessoal, positiva ou negativa, sobre seu próprio comportamento (Liñán \& Chen, 2009; Oliveira, Vieira, Laguía, Moriano, \& Soares 2016). Por meio da regressão, evidenciou-se que essa avaliação ou percepção comportamental não influencia a motivação para aprender dos alunos pesquisados. 
Em seguida, realizou-se a regressão para verificar a relação entre a dimensão NS e as variáveis do perfil (independentes) com MA (dependente). No que diz respeito a essa análise, devido ao valor de $\mathrm{R}^{2}$ (,089), destaca-se que quanto maior o valor do Coeficiente de determinação maior a qualidade do modelo (Hair Jr. et al., 2009), constata-se baixa qualidade do modelo. Por conseguinte, na Tabela 6, apresentam-se os coeficientes para o modelo de regressão da dimensão de NS e perfil com MA.

Tabela 6

Coeficientes para o modelo da dimensão de NS e perfill

\begin{tabular}{|c|c|c|c|c|c|c|}
\hline \multicolumn{2}{|c|}{ Modelo } & \multicolumn{2}{|c|}{ Coef. não padronizados } & \multirow{2}{*}{$\begin{array}{c}\begin{array}{c}\text { Coef. } \\
\text { padronizados }\end{array} \\
\text { Beta } \\
\end{array}$} & \multirow[t]{2}{*}{$\mathrm{t}$} & \multirow[t]{2}{*}{ Sig } \\
\hline & & B & Erro Padrão & & & \\
\hline \multirow{8}{*}{ NS e Perfil } & (Constante) & 12,687 & 3,127 & & 4,057 &, 000 \\
\hline & Semestre &,- 159 & ,143 &,- 086 & $-1,110$ & ,269 \\
\hline & Sexo & 2,528 & ,707 & ,253 & 3,577 & 000 \\
\hline & Idade &, 228 & ,447 & ,038 &, 509 & ,611 \\
\hline & Trabalha & 291 & ,750 & ,029 & ,388 & 698 \\
\hline & CDiscEmpr &,- 075 & ,783 &,- 007 &,- 095 & ,924 \\
\hline & AtivEmpr &,- 376 & ,735 &,- 037 &,- 512 & 609 \\
\hline & $\mathrm{AP}$ & 206 & 118 & 126 & 1,744 & 083 \\
\hline
\end{tabular}

Fonte: elaborado pelos autores.

O modelo da dimensão de NS e perfil com MA apresentou significância (10\%) apenas para a dimensão de NS e sexo (Tabela 6). As demais variáveis não independentes não se mostraram estatisticamente relevantes para prever MA. Nesse sentido, existe $90 \%$ de chance da dimensão de NS e a variável sexo influenciar MA. A dimensão de NS reflete a percepção de que as pessoas tidas como referência para o indivíduo irão ou não aprovar a decisão de se tornar um empreendedor (Liñán \& Chen, 2009). Quanto ao sexo, cabe resgatar que a amostra é homogênea, com pequeno predomínio dos homens. Nesse sentido, Pansera, Valentini, Souza e Berleze (2016) afirmam que a motivação é um determinante para o nível e a qualidade da aprendizagem, e que há semelhanças na orientação motivacional entre os sexos masculino e feminino. Ainda, observando a comparação descritiva entre os sexos, aponta-se que as alunas são altamente motivadas a aprender, enquanto os alunos encontram-se moderadamente motivados.

Essa dimensão compreende o componente mais social do QIE, na medida em que incorpora a influência de pessoas significativas para o sujeito na decisão de desenvolver a sua carreira profissional (Oliveira et al., 2016). Isso vai ao encontro do resultado auferido, demonstrando que os familiares, companheiros, amigos, colegas de trabalho e de graduação influenciam na motivação em aprender dos estudantes de Ciências Contábeis da UFSM. 
Ainda, analisou-se a relação entre a dimensão PC e as variáveis do perfil (sexo, idade, se trabalha, se já cursou disciplina de empreendedorismo, se exerce atividade empreendedora), variáveis independentes, com a variável dependente MA. Semelhante ao verificado em NS e AP, o $\mathrm{R}^{2}$ apresentou baixo valor, demonstrando um modelo com pouca qualidade. Na Tabela 7, apresentam-se os coeficientes para o modelo da dimensão de PC e as variáveis do perfil.

Tabela 7

Coeficientes do modelo da dimensão de PC e perfil

\begin{tabular}{|c|c|c|c|c|c|c|}
\hline \multicolumn{2}{|c|}{ Modelo } & \multicolumn{2}{|c|}{ Coef. não padronizados } & \multirow{2}{*}{$\begin{array}{c}\begin{array}{c}\text { Coef. } \\
\text { padronizados }\end{array} \\
\text { Beta } \\
\end{array}$} & \multirow[t]{2}{*}{$t$} & \multirow[t]{2}{*}{ Sig } \\
\hline & & B & Erro Padrão & & & \\
\hline \multirow{8}{*}{ PC e Perfil } & (Constante) & 14,781 & 2,912 & & 5,076 &, 000 \\
\hline & Semestre &,- 150 & ,145 &,- 081 & $-1,035$ & ,302 \\
\hline & Sexo & 2,600 & ,711 & ,261 & 3,660 &, 000 \\
\hline & Idade & 191 & ,450 & ,032 & ,423 & ,673 \\
\hline & Trabalha & 109 & ,747 &, 011 & , 146 & ,884 \\
\hline & CDiscEmpr &,- 014 & 790 &,- 001 &,- 018 & ,986 \\
\hline & AtivEmpr &,- 400 & ,754 &,- 039 &,- 530 & ,597 \\
\hline & AP & 067 & ,085 & ,058 & ,786 & ,433 \\
\hline
\end{tabular}

Fonte: elaborado pelos autores.

Diante da Tabela 7, observa-se que as relações entre a dimensão de PC e as variáveis de perfil com MA não se mostraram significativas, com exceção da variável sexo. Assim, a partir deste modelo, existe significativa chance de apenas a variável sexo influenciar MA. As demais variáveis indicativas do perfil e PC não se revelaram importantes estatisticamente para explicar as variações de MA. Cabe destacar que na dimensão PC o indivíduo manifesta comportamentos que acha que são capazes de controlar e dominar (Bandura, 1982).

Para Liñán e Chen (2009), esse controle comportamental percebido inclui não apenas a sensação de poder, mas também a percepção sobre a controlabilidade do comportamento. Infere-se que a partir do modelo de regressão apresentado para as variáveis independentes PC e perfil com relação à MA, a percepção de controle comportamental não se mostrou significativa para explicar a motivação para aprender dos estudantes de Ciências Contábeis. 
Em seguida, buscou-se verificar se existe relação entre a dimensão de IE e as variáveis do perfil, variáveis explicativas, com a variável dependente MA. No que diz respeito à qualidade do modelo, observouse um valor baixo de $\mathrm{R}^{2}$, denotando que as variáveis determinadas para explicar o comportamento de $\mathrm{MA}$ apresentam baixo poder explicativo. Na Tabela 8, constam os coeficientes para esse modelo.

Tabela 8

Coeficientes modelo da dimensão de IE e perfil

\begin{tabular}{|c|c|c|c|c|c|c|}
\hline \multicolumn{2}{|c|}{ Modelo } & \multicolumn{2}{|c|}{ Coef. não padronizados } & \multirow{2}{*}{$\begin{array}{c}\begin{array}{c}\text { Coef. } \\
\text { padronizados }\end{array} \\
\text { Beta } \\
\end{array}$} & \multirow[t]{2}{*}{$\mathrm{t}$} & \multirow[t]{2}{*}{ Sig } \\
\hline & & B & Erro Padrão & & & \\
\hline \multirow{8}{*}{ IE e Perfil } & (Constante) & 13,369 & 2,869 & & 4,659 & 000 \\
\hline & Semestre &,- 145 & ,143 &,- 079 & $-1,019$ & ,309 \\
\hline & Sexo & 2,689 & ,707 & ,270 & 3,803 & ,000 \\
\hline & Idade & 190 &, 447 & 032 &, 426 & 670 \\
\hline & Trabalha & ,142 & ,741 & , 014 & ,191 & 849 \\
\hline & CDiscEmpr &,- 023 & 783 &,- 002 &,- 030 & 976 \\
\hline & AtivEmpr &,- 132 & ,760 &,- 013 &,- 174 & 862 \\
\hline & $\mathrm{AP}$ & ,112 & ,060 & 137 & 1,859 & 065 \\
\hline
\end{tabular}

Fonte: elaborado pelos autores.

A partir da Tabela 8, para o modelo da dimensão de IE e perfil, relacionados com MA, mostrou-se significativo apenas IE e sexo, evidenciando coeficientes de correlação positivos e demonstrando relação sobre MA. O modelo se apresentou significativo a $10 \%$ de probabilidade, dessa maneira, existe $90 \%$ de chance da dimensão de IE e a variável sexo influenciarem MA. As demais variáveis indicativas do perfil não se revelaram importantes estatisticamente para explicar as variações de MA.

No que diz respeito à IE, quanto mais forte a intenção de um indivíduo de se engajar em um comportamento específico, mais provável é que o comportamento real será realizado (Liñán \& Chen, 2009). Isso reforça o resultado obtido na regressão, na qual evidenciou-se que a dimensão comportamental relacionada à intenção em empreender consegue prever a motivação para aprender dos futuros bacharéis em Ciências Contábeis da UFSM.

A partir das regressões realizadas entre QIE, Perfil e MA, verificaram-se relações entre algumas das dimensões individuais do QIE e uma variável do perfil, sexo, com MA. As relações significativas explicativas para MA ocorreram nas dimensões de NS e IE, indicando que, para os alunos pesquisados, a motivação em aprender é influenciada/explicada pela pressão social exercida para realizar ou não um comportamento e reflete o efeito dos valores sociais sobre o indivíduo (NS) (Morales, Rebolloso, \& Moya, 1994). Ou seja, demonstra a interferência, o peso, a importância de pessoas significativas para o aluno e o reflexo dessa influência na motivação para aprender.

Indica, ainda, que a motivação em aprender desses alunos também pode ser explicada pela dimensão IE, que representa um objetivo que o indivíduo almeja alcançar e o planejamento que fundamentará a busca pela concretude desse objetivo (Tubbs, \& Ekerberg, 1991), como empreender.

Assim, entende-se que a MA pode ser explicada pela IE, visto que a intenção de um indivíduo está intrinsecamente ligada ao seu comportamento, logo, entende-se que todo o comportamento é precedido de uma intenção (Krueger et al., 2000). Com base nisso, refuta-se a hipótese nula e aceita-se a hipótese alternativa, por meio da qual aceita-se que existe relação significativa positiva entre intenção empreendedora e motivação para aprender dos estudantes de Ciências Contábeis da UFSM. 
Isso revela a importância do incentivo em empreender na graduação em Ciências Contábeis, visto que pode influenciar a motivação em aprender. De modo geral, estes resultados contribuem para um melhor entendimento do primeiro modelo apresentado, no qual observou-se uma relação significa do QIE (formado pelo conjunto entre AP, NS, PC e IE) com MA.

\section{Considerações Finais}

Este estudo teve como objetivo analisar a relação entre intenção empreendedora e motivação para aprender dos estudantes de Ciências Contábeis da UFSM. No intuito de alcançar tal objetivo, a partir de uma amostra de 219 alunos, inicialmente identificou-se o perfil dos alunos de Ciências Contábeis da UFSM pesquisados. De modo geral, a amostra é composta por alunos do sexo masculino, entre 18 e 23 anos de idade, que estudam no turno noturno, que não trabalham, que nunca cursaram disciplina relacionada ao empreendedorismo e que já exerceram, ou alguém da família já exerceu, atividades empreendedoras.

Em seguida, mensurou-se a motivação para aprender desses alunos, de acordo com o instrumento proposto por Tho (2017). A motivação para aprender corresponde a aspectos que tendem a influenciar a forma como os alunos irão se comportar em sala de aula, aproveitando as condições de ensino, para que ocorra a aquisição de novos conhecimentos (Tho, 2017). Verificou-se que os alunos pesquisados apresentam motivação para aprender em razão considerada moderada.

Posteriormente, mediu-se a intenção empreendedora dos alunos pesquisados, de acordo com o instrumento proposto por Liñán e Chen (2009). Constatou-se que atitudes pessoais e normas subjetivas figuram em alta razão, o que demonstra que os alunos apresentam interesse/boa impressão sobre ser empreendedor, e que as pessoas de referência têm influência na decisão deles de se tornarem empreendedores. Enquanto que percepção comportamental e intenção empreendedora constam em razão moderada. Em relação ao trabalho, concluiu-se que os alunos que estão trabalhando têm maior intenção em empreender, no entanto, sentem-se menos motivados a aprender, o que pode ser justificado pelo fato de terem menos tempo para se dedicar aos estudos.

Ainda, associou-se os constructos de motivação para aprender e intenção empreendedora. Na correlação entre QIE e MA, não se evidenciou associação significativa. No entanto, ocorreram associações significativas entre as dimensões do QIE. Houve associação positiva forte entre atitude pessoal e percepção comportamental, e entre atitude pessoal e intenção empreendedora, por meio da qual é possível concluir que os acadêmicos veem o empreendedorismo como uma opção profissional. Já a associação de normas subjetivas e intenção empreendedora apresentou correlação positiva fraca, de maneira que se conclui que, para os acadêmicos pesquisados, $\mathrm{o}$ apoio ou não das pessoas de referência representa fraca associação na pretensão de empreender.

Por fim, determinou-se a influência da intenção empreendedora na motivação para aprender. A partir das regressões realizadas, evidenciou-se que a intenção empreendedora, por meio do QIE, influencia a motivação para aprender. Aprofundando as análises, por meio de regressões entre QIE e Perfil com motivação para aprender, verificaram-se relações significativas para as dimensões de normas subjetivas e intenção empreendedora, e a variável sexo como sendo explicativas para motivação para aprender.

Logo, apesar da correlação dos constructos não demonstrar associação significativa entre essas temáticas, a partir da análise das regressões conclui-se que a intenção empreendedora, enquanto conjunto de suas dimensões, apresenta relação significativa positiva com a motivação para aprender, justificada principalmente pelas dimensões de normas subjetivas e intenção empreendedora, reforçando a relevância das pessoas de referência do aluno, bem como o estímulo ao empreendedorismo. 
As contribuições possibilitam aos alunos um maior entendimento quanto aos seus aspectos comportamentais, quanto à motivação para aprender e intenção empreendedora. Essa racionalização pode potencializar a promoção do empreendedorismo não apenas como uma opção profissional, mas também instiga o desenvolvimento de um comportamento mais empreendedor. Além dos alunos, este estudo pode apresentar contribuições para os docentes do curso pesquisado.

Por meio dos resultados elucidados, os docentes podem ter conhecimento sobre a intenção empreendedora e a motivação para aprender dos seus alunos, fator que pode fomentar um ensino mais empreendedor e desencadear melhorias na forma de ensino-aprendizagem utilizada. Outra contribuição refere-se à possibilidade de reaplicabilidade da pesquisa, possibilitando-se a analisar o comportamento empreendedor e motivacional de estudantes de diferentes cursos e instituições.

O estudo limitou-se a um corte transversal, compreendendo um único período analisado, bem como considerando apenas alunos de graduação em Ciências Contábeis de uma instituição de ensino superior pública. Além disso, limitou-se a uma abordagem quantitativa com a aplicação de questionário para coleta de dados e análise estatística, considerando os constructos já validados. Ainda, menciona-se que o Coeficiente de determinação demonstrou baixa qualidade do modelo analisado, o que pode limitar inferências adequadas.

Para estudos futuros, sugere-se replicar a pesquisa de modo longitudinal, contemplando uma maior quantidade de períodos analisados, bem como considerando mais ou outros cursos de graduação, tanto de instituição de ensino pública quanto privada. Recomenda-se, ainda, uma análise qualitativa para coleta e análise dos dados e incentiva-se a utilização de outros testes estatísticos que possam confirmar ou melhorar o poder de explicação. Além disso, outros constructos comportamentais podem ser considerados como a atitude empreendedora e o comprometimento.

\section{Referências}

Ajzen, I. (1991). The theory of planned behavior. Organizational Behavior and Human Decision Processes, 50(2), 179-211. Doi: https://doi.org/10.1016/0749-5978(91)90020-T

Ajzen, I. (2001). Nature and operation of attitudes. Annual Review of Psychology, 52(1), 27-58. Doi:https:// doi.org/10.1146/annurev.psych.52.1.27

Bandura, A. (1982). Self-efficacy mechanism in human agency. American Psychology, 37(2), 122-147. Doi: https://doi.org/10.1037/0003-066X.37.2.122

Barak, M., Watted, A., \& Haick, H. (2016). Motivation to learn in massive open online courses: Examining aspects of language and social engagement. Computers \& Education, 94, 49-60. Doi:https://doi. org/10.1016/j.compedu.2015.11.010

Becker, J. L. (2015). Estatística básica: transformando dados em informação. Bookman Edit.

Beck, F., \& Rausch, R. B. (2015). Fatores que influenciam o processo ensino-aprendizagem na percepção de discentes do curso de Ciências Contábeis. Contabilidade Vista \& Revista, 25(2), p. 38-58. Recuperado de https://revistas.face.ufmg.br/index.php/contabilidadevistaerevista/article/view/1727

Cantner, U., Goethner, M., \& Silbereisen, R. K. (2017). Schumpeter's entrepreneur - A rare case. Journal of Evolutionary Economics, 27(1), 187-214. Doi: https://doi.org/10.1007/s00191-016-0467-3

Cavalcante, C. H. L. (2012). Percepção dos alunos iniciantes e concluintes do curso de Ciências Contábeis sobre a profissão contábil. Revista Brasileira de Contabilidade, 177, 50-63.

Cole, M. S., Harris, S. G., \& Feild, H. S. (2004). Stages of Learning Motivation: Development and Validation of a Measure 1. Journal of Applied Social Psychology, 34(7), p. 1421-1456. Doi: https:// doi.org/10.1111/j.1559-1816.2004.tb02013.x 
Fayolle, A., \& Liñán, F. (2014). The future of research on entrepreneurial intentions. Journal of Business Research, 67(5), 663-666. Doi: https://doi.org/10.1016/j.jbusres.2013.11.024

Gieure, C., Benavides-Espinosa, M. D. M., \& Roig-Dobón, S. (2020). The entrepreneurial process: the link between intentions and behavior. Journal of Business Research, 112, 541-548. Doi: https://doi. org/10.1016/j.jbusres.2019.11.088

Gopalan, V., Bakar, J. A. A., Zulkifli, A. N., Alwi, A., \& Mat, R. C. (2017). A review of the motivation theories in learning. In: The 2nd International Conference on Applied Science and Technology 2017 (ICAST'17). AIP Conference Proceedings 1891.

Hair Jr., J. F., Black, W. C., Babin, B. J., Anderson, R. E., \& Tatham, R. L. (2009). Análise multivariada de dados. 6. ed. Porto Alegre: Bookman.

Hecke, A. P. (2011). A intenção empreendedora dos alunos concluintes dos cursos de graduação em Administração em Ciências Contábeis das instituições de ensino superior de Curitiba-PR. Dissertação de Mestrado (Contabilidade), UFPR, Curitiba, PR, Brasil.

Hulley, S. B., Cummings, S. R., Browner, W. S., Grady, D., Hearst, N., \& Newman, T. B. (2003). Delineando a pesquisa clínica: uma abordagem epidemiológica. (2a ed.). Porto Alegre: Editora Artmed.

Iwu, C. G., Oputeb, P. A., Nchuc, R., Eresia-Ekef, C., Tengehc, R. K., Jaiyeobad, O., \& Aliyue, O. A. (2019). Entrepreneurship education, curriculum and lecturer-competency as antecedents of student entrepreneurial intention. The International Journal of Management Education, 100295. Doi: https:// doi.org/10.1016/j.ijme.2019.03.007

Jena, R. K. (2020). Measuring the Impact of Business Management Student's Attitude towards Entrepreneurship Education on Entrepreneurial Intention: A Case Study. Computers in Human Behavior, 107, 106275. Doi: https://doi.org/10.1016/j.chb.2020.106275

Krueger, N. F. (2017). Entrepreneurial intentions are dead: Long live entrepreneurial intentions. In Brännback, M. \& Carsrud, A. L. (Eds). Revisiting the entrepreneurial mind (p. 13-34). Switzerland: Springer, Cham.

Krueger, N. F., Reilly, M. D., \& Carsrud, A. L. (2000). Competing models of entrepreneurial intentions. Journal of Business Venturing, 15, 411-432. Doi: https://doi.org/10.1016/S0883-9026(98)00033-0

Krüger, C. (2019). Modelo de mensuração do comportamento empreendedor a partir de características comportamentais e intenção empreendedora. Tese de Doutorado (Administração). UFSM, Santa Maria, RS, 2019.

Krüger, C., Bürger, R. E., \& Minello, I. F. (2019). O papel moderador da educação empreendedora diante da intenção empreendedora. Revista Economia \& Gestão, 19(52). Doi: https://doi.org/10.5752/P.19846606.2019v19n52p61-81

Krüger, C., Borré, M. L., Lopes, L. F. D. \& Michelin, C. F. (2021). O binômio liderança-empreendedorismo: uma análise a partir do comportamento planejado. Perspectivas Online: Humanas \& Sociais Aplicadas, 11(31), 26-45. Doi: https://doi.org/10.25242/8876113120212305

Liñán, F., \& Chen, Y. W. (2009). Development and cross-cultural application of a specific instrument to measure entrepreneurial intentions. Entrepreneurship theory and practice, 33(3), 593-617. Doi: https://doi.org/10.1111/j.1540-6520.2009.00318.x

Liñán, F., Rodríguez-Cohard, J. C., \& Rueda-Cantuche, J. M. (2011). Factors affecting entrepreneurial intention levels: a role for education. International Entrepreneurship and Management Journal, 7(2),195-218. Doi: https://doi.org/10.1007/s11365-010-0154-z 
Liñán, F., \& Fernandez-Serrano, J. (2014). National culture, entrepreneurship and economic development: different patterns across the European Union. Small Bus. Econ, 42, 685-701. Doi: https://doi. org/10.1007/s11187-013-9520-x

Loiola, E., Gondimi, S. M. G., Pereira, C. R., \& Ferreira, A. S. M. (2012). Ação planejada e intenção empreendedora entre universitários: analisando preditores e mediadores. Revista Psicologia Organizações e Trabalho, 16(1). Doi: https://doi.org/10.17652/rpot/2016.1.706

Lopes, L. F. D. (2016). Métodos quantitativos. 1. ed. Universidade Federal de Santa Maria.

Lourenço, A. A., \& Paiva, M. O. A. de. (2010). A Motivação Escolar e o Processo de Aprendizagem. Ciências e Cognição, 15(2). Recuperado de http://cienciasecognicao.org/revista/index.php/cec/article/view/313

Malacarne, R., Brunstein, J., \& Brito, M. D. (2014). Formação de técnicos agropecuários empreendedores: o caso do IFES e sua participação na OBAP. REGEPE, 3(2), 20-41. Doi: http://dx.doi.org/10.14211/ regepe.v3i2.125

Marion, J. C. (1996). O ensino de contabilidade. São Paulo: atlas.

Minello, I. F., Bürger, R. E., \& Krüger, C. (2017). Características comportamentais empreendedoras: um estudo com acadêmicos de Administração de uma universidade brasileira. Revista de Administração da Universidade Federal de Santa Maria, 10, 72-91. Doi: http://dx.doi.org/10.5902/19834659 24894

Mirjana, P. B., Ana, A., \& Marjana, M. S. (2018). Examining determinants of entrepreneurial intentions in Slovenia: applying the theory of planned behaviour and an innovative cognitive style. Economic Research-Ekonomska Istrazivanj, 31, 1453-147. Doi: https://doi.org/10.1080/1331677X.2018.1478321

Morales, J. F., Rebolloso, E., \& Moya, M. (1994). Actitudes. Em J. F. Morales (Ed.), Psicología Social. Madrid, España: McGraw-Hill, p. 495-621.

Moreira, H., \& Caleffe, L. G. (2008). Metodologia da pesquisa para o professor pesquisador. 2. ed. Rio de Janeiro: Lamparino.

Nguyen, T. T. M., \& Nguyen, T. D. (2010). "Determinants of learning performance of business students in a transitional market", Quality Assurance in Education, 18(4), p. 304-316. Doi: https://doi. org/10.1108/09684881011079152

Oliveira, B. M. F., Vieira, D. A., Laguía, A., Moriano, J. A., \& Soares, V. J. S. (2016). Intenção empreendedora em estudantes universitários: adaptação e validação de uma escala (QIE). Avaliação Psicológica, 15(2) 187-196. Doi: https://doi.org/10.15689/ap.2016.1502.07

Omri, A. (2020). Formal versus informal entrepreneurship in emerging economies: the roles of governance and the financial sector. Journal of Business Research, 108, 277-290. Doi: https://doi.org/10.1016/j. jbusres.2019.11.027

Özpeynirci, R. Yücenurşen, M., Apakc, I., \& Polatc, Y. (2015). A Comparative Analysis of Accounting Education's Effectiveness with the Balanced Scorecard Method: A Case Study of KMU. ProcediaSocial and Behavioral Sciences, 174, 1849-1858. Doi: https://doi.org/10.1016/j.sbspro.2015.01.847

Paiva, A. L., Andrade, D. M., Antonialli, L. M., \& Brito, M. J. (2018). Strategic entrepreneurship: observations from the practices of cachaça certification. RAM. Revista de Administração Mackenzie, 19(2), eRAMG180099. Doi: https://doi.org/10.1590/1678-6971/eramg180099

Pansera, S. M., Valentini, N. C., Souza, M. S., \& Berleze, A. (2016). Motivação intrínseca e extrínseca: diferenças no sexo e na idade. Psicologia Escolar e Educacional, SP. 20(2), Maio/Agosto, 313-320. Doi: https://doi.org/10.1590/2175-353920150202972 
Porto, R. C., \& Gonçalves, M. P. (2017). Motivação e envolvimento acadêmico: um estudo com estudantes universitários. Psicologia Escolar e Educacional, 21(3) Set/Dez, 515-522. Doi: https:// doi.org/10.1590/2175-35392017021311192

Reyad, S., Al-Sartawi, A. M., Badawi, S., \& Hamdan, A. (2019). Do entrepreneurial skills affect entrepreneurship attitudes in accounting education. Higher Education, Skills and Work-based Learning, 9, 739-757. Doi: https://doi.org/10.1108/HESWBL-01-2019-0013

Sampieri, R. H., Collado, C. F., \& Lucio, M. del P. B. (2013). Metodologia de pesquisa. 5. ed. Porto Alegre: Penso.

Santos, E. A. dos, Moura, I. V., \& Almeida, L. B. de. (2018). Intenção dos Alunos em Seguir Carreira na Área de Contabilidade sob a Perspectiva da Teoria do Comportamento Planejado. Revista de Educação e Pesquisa em Contabilidade (REPeC), 12(1). Doi: https://doi.org/10.17524/repec.v12i1.1635

Schaefer, R. (2018). Empreender como uma forma de ser, saber e fazer: o desenvolvimento da mentalidade e do comportamento empreendedores por meio da educação empreendedora. Tese de Doutorado (Administração). UFSM, Santa Maria, RS, Brasil.

Silva, I., Nasu, V., Leal, E., \& Miranda, G. (2020). Fatores determinantes da evasão nos cursos de ciências contábeis no Brasil. Revista Gestão Universitária na América Latina - GUAL, 13(1), 48-69. Doi: https://doi.org/10.5007/1983-4535.2020v13n1p48

Silva, L. M. da, Krüger, C., Minello, I. F., \& Ghilardi, W. J. (2019). Empregado ou Empresário? A Intenção Empreendedora de Alunos de Graduação em Ciências Contábeis. Saber Humano: Revista Científica da Faculdade Antônio Meneghetti, 9, 77-109. Doi: https://doi.org/10.18815/sh.2019v9n14.355

Souza, A., Avelar, E., Boina, T., \& Rodrigues, L. (2009). Ensino da Contabilidade Gerencial: estudo dos cursos de Ciências Contábeis das melhores universidades brasileiras. Revista Contemporânea de Contabilidade, 5(10), 69-90. Doi: 10.5007/2175-8069.2008v5n10p69

Souza, G. H., Santos, P. C. F., Lima, N. C., Cruz, N. J. T. \& Lezana, A. G. R. (2016). O potencial empreendedor e o sucesso empresarial: Um estudo sobre elementos de convergência e explicação. Revista de Administração Mackenzie, 17(5), 188-215. Doi: http://dx.doi.org/10.1590/1678-69712016/ administracao.v17n5p188-215

Tho, N. D. (2017). Knowledge transfer from business schools to business organizations: the roles absorptive capacity, learning motivation, acquired knowledge and job autonomy. Journal of Knowledge Management, 21(5), 1240-1253. Doi: https://doi.org/10.1108/JKM-08-2016-0349

Tubbs, M., \& Ekerberg, S. (1991). The role of intentions of work motivations: Implications for goalsetting theory and research. Academy of Management Review, 16(1), 180-199. Doi: https://doi. org/10.2307/258611

Vieira, F. D., \& Rodrigues, C. S. (2014). Os estudantes de engenharia e as suas intenções empreendedoras. Revista produção online, 14(1), 242-263. Doi: https://doi.org/10.14488/1676-1901.v14.i1.1588 